\title{
Correlation between QT Interval with Left Ventricular Mass Index (Using M-Mode Echocardiography) and Blood Pressure in Patients with Hypertension
}

\author{
Budi Susetyo Pikir¹, Priscillia Myriarda ${ }^{2}$ \\ ${ }^{1}$ Professor in Department of Cardiology and Vascular Medicine, ${ }^{2}$ Student in Department of Cardiology and \\ Vascular Medicine, Faculty of Medicine-Dr. Soetomo Academic General Medicine, Universitas Airlangga, \\ Surabaya, East Java, Indonesia
}

\begin{abstract}
Background: In patients with hypertension, the excessive blood pressure load correlates with neurohormonal activities and will lead to left ventricular remodeling. QT interval often occurs in patients with hypertension. The correlation between structural changes and repolarization remains unclear.

Method: This study involved 62 patients with hypertension (38 female and 24 male) to whom blood pressure, electrocardiogram and echocardiography examination were performed simultaneously. The correlation between QT interval with left ventricle mass index and blood pressure was statistically analyzed using Pearson correlation test.

Results: The mean of QTc interval in patients with hypertension was $390.40 \pm 30.73$ millisecond. Based on the echocardiography examination results, the mean of left ventricular mass index was $75.38 \pm 12.36$ with RWT of $0.36 \pm 0.06$. Pearson correlation statistical analysis shows a correlation between QTc interval with left ventricular mass index $(\mathrm{r}=0.277$; $\mathrm{p}$ value $=0.030)$ and systolic blood pressure $(\mathrm{r}=0.317 ; \mathrm{p}$ value $=0,014)$.

Conclusion: QT interval correlated with increased left ventricular mass index and systolic blood pressure in hypertension patients with normal geometry and concentric remodeling.
\end{abstract}

Keywords: QT interval, left ventricular mass index, blood pressure, hypertension.

\section{Introduction}

Hypertension is considered the primary cause of morbidity and mortality in cardiovascular. In 2000, hypertension occurred in nearly 1,000 million people or almost $26 \%$ of adult population globally, 333 million people in developing countries and 639 million in underdeveloped countries ${ }^{(1)}$. According to epidemiology

\section{Corresponding Author:}

\section{Budi Susetyo Pikir}

Department of Cardiology and Vascular Medicine, Faculty of Medicine, Faculty of Medicine-Dr. Soetomo Academic General Medicine, Universitas Airlangga, Surabaya, East Java, Indonesia e-mail: pikirbudi10@gmail.com/bsp49@fk.unair.ac.id data in America, hypertension prevalence in 2004 reached up to $29 \%$ and increased to $34 \%$ in 2006 , while in Indonesia was $32.2 \%^{(2)}$.

Hypertension is defined as the persistent increase of blood pressure to above 140/90 $\mathrm{mmHg}$. High blood pressure is a long-term health problem that most frequently send people to health facilities ${ }^{(3)}$. American Heart Association has predicted that the total cost for hypertension in 2010 would reach 76,600 million dollars. The data in America reported that of all the patients, $80 \%$ knew their diseases, $71 \%$ following routine medication and $48 \%$ could achieve controlled blood pressure ${ }^{(4)}$.

Uncontrolled hypertension increase the risk of coronary heart disease, stroke and heart failure. Heart failure could occur due long-term hypertension or due to 
secondary results of coronary heart disease. Continuous high blood pressure stimulus will lead to remodeling and left ventricular hypertrophy. Left ventricle remodeling is a structural changes (dimension, mass and form) of the heart as the response to the hemodynamic loads related to neurohormonal activation ${ }^{(5)}$.

Until recently, electrocardiogram is still considered an important diagnostic tool in cardiology. Electrocardiogram examination in hypertension patients showed several abnormalities, i.e. QRS complex expansion (as the appearance of left ventricle hypertrophy), QT interval elongation etc. QT interval depicts the total amount of time required to activate and to relax the ventricle ${ }^{(6)}$.

Clinically speaking, left ventricular hypertrophy is more often detected using echocardiography (EKG). In echocardiography, left ventricular hypertrophy can be detected more accurately by evaluating the wall thickness and/or left ventricular mass index towards body size. Several criteria of LVH in EKG are highly specific but less sensitive. Several previous studies showed a correlation between left ventricle hypertrophy and EKG repolarization changes, such as QT interval elongation $^{(7)}$. Although several evidences have confirmed that repolarization impairment is the initial process, but the correlation between the effect of light ventricular hypertrophy or left ventricular structural changes with
EKG repolarization remains unclear. This study aims to analyze the correlation between QT interval with left ventricular mass index and blood pressure in patients with hypertension.

\section{Method}

This is an analytical observational study which used cross-sectional approach or design. It was conducted in Department of Cardiology and Vascular Medicine, Dr. Soetomo General Hospital Surabaya from October to December 2012. The samples of this study were patients with hypertension undergoing outpatient treatment in cardiology unit of Dr. Soetomo General Hospital Surabaya from November 2012 who met the inclusion criterion (having normal left ventricular ejection fraction with $\mathrm{EF}>55 \%$ ) and were willing to be enrolled in the study procedure as shown by their signing the informed consent ${ }^{(8)}$.

The samples were 62 patients with hypertension who were treated in outpatient cardiology unit and underwent echocardiography examination. The data were analyzed using SPSS 17.0 program for Windows (SPSS, Inc., Chicago. IL). One-sample Kolgomorov-Smirnov test was used to test the normality of data distribution. Intraobserver and inter-observer variability were evaluated using correlation test, Bland Altman test and variability percentage. The results were considered significant if the $\mathrm{p}$ significance value was $<0.05^{(9)}$.

\section{Results}

Table 1. Respondents' basic characteristics

\begin{tabular}{|l|c|c|c|}
\hline N $=\mathbf{6 2}$ & Mean \pm SD & Minimum & Maximum \\
\hline Gender & \multicolumn{3}{|c|}{$+=38 ; \partial^{\Uparrow}=24$} \\
\hline Age & $56.94 \pm 7.34$ & 40 & 15 \\
\hline Hypertension period & $5.73 \pm 3.36$ & 0.5 & 29.7 \\
\hline BMI & $24.25 \pm 3.47$ & 15.4 & 160 \\
\hline Systolic blood pressure & $132.66 \pm 14.16$ & 100 & 95 \\
\hline Diastolic blood pressure & $80.24 \pm 9.93$ & 60 & 97 \\
\hline Heart rate & $75.79 \pm 10.31$ & 56 & 480 \\
\hline QTc & $390.40 \pm 30.73$ & 320 & \\
\hline
\end{tabular}

Based on gender, there were 38 female samples (61\%) and 24 male samples (39\%) with ages varied between $40-75$ years old and age mean of $56 \pm 7.3$ years old. The samples' length of hypertension period ranged between 2-15 years with the mean of $5.7 \pm 3.3$ years.
The mean of the samples' QT interval based on EKG examination was $390.4 \pm 30.7$ millisecond. The means of systolic and diastolic blood pressure were $132.6 \pm 14.2$ and $80.24 \pm 9.9$ respectively. 
Table 2. Table of intra and interobserv

\begin{tabular}{|c|c|c|c|c|c|c|}
\hline \multirow{2}{*}{ Parameter } & \multicolumn{2}{|c|}{ Intra-observer } & \multirow{2}{*}{$\begin{array}{c}\% \text { Intra-observer } \\
\text { Variability }\end{array}$} & \multicolumn{2}{|c|}{ Inter-observer } & \multirow{2}{*}{$\begin{array}{c}\% \text { Inter-observer } \\
\text { Variability }\end{array}$} \\
\hline & $\mathbf{R}$ & Mean diff (SD) & & $\mathbf{R}$ & Mean diff (SD) & \\
\hline LVMI & 0.92 & $0.55+4.73 \mathrm{p}=0.66$ & $0.72+2.39$ & 0.96 & $0.56+3.28 \mathrm{p}=0.52$ & $0.73+1.66$ \\
\hline RWT & 0.72 & $1.80+8.57 \mathrm{p}=0.43$ & $3.05+4.33$ & 0.83 & $1.40+6.67 \mathrm{p}=0.43$ & $2.36+3.37$ \\
\hline
\end{tabular}

Intra-observer and inter-observer evaluation was conducted for LVMI, while Bland Altman method was used for RWT. The evaluations were performed in 15 patients. The analysis results showed that most patients had a significant intra-observer and inter-observer correlation and inter-observer variability of $<5 \%$.

Table 3. Data normality analysis

\begin{tabular}{|l|c|c|c|}
\hline \multirow{2}{*}{ Variable } & \multicolumn{3}{|c|}{ Kolmogorov-Smirnov (a) } \\
\cline { 2 - 4 } & Statistic & Df & 0.200 \\
\hline LVMI & 0.158 & 62 & 0.200 \\
\hline RWT & 0.207 & 62 & 0.054 \\
\hline Systolic blood pressure & 0.197 & 62 & 0.000 \\
\hline Diastolic blood pressure & 0.228 & 62 & 0.122 \\
\hline QT interval & 0.197 & 62 & \\
\hline
\end{tabular}

The results of data normality conducted in the study's variables showed a normal distribution in the variable QT interval based on Kolmogorov-Smirnov significant value $(\mathrm{p}>0.05)$. To find out the correlation between QT interval and left ventricular mass index, Pearson correlation test was performed on the respondents' RWT and systolic blood pressure which were evaluated using M-mode echocardiography. The correlation between QT interval and blood pressure was tested using Spearman method.

Table 4. Correlation between QT interval with respondents' left ventricular mass index and blood pressure

\begin{tabular}{|l|c|c|}
\hline \multirow{2}{*}{ Variable (n=62) } & \multicolumn{2}{|c|}{ QTc } \\
\cline { 2 - 3 } & Correlation & P value \\
\hline LVMI & $\mathrm{r}=0.277$ & 0,030 \\
\hline RWT & $\mathrm{r}=0.215$ & 0.093 \\
\hline Systolic blood pressure & $\mathrm{r}=0.312$ & 0,014 \\
\hline Diastolic blood pressure & $\mathrm{r}_{\mathrm{s}}=0.031$ & 0.813 \\
\hline
\end{tabular}

Table above shows that diastolic blood pressure has

higher than LVMI in terms of correlation value. higher P value than systolic. The P value of RWT also

Table 5. Basic characteristics of the respondents based on echocardiography examination

\begin{tabular}{|l|c|c|c|}
\hline & Normal Echo $($ Rerata \pm SD) & Left Ventricular Remodeling (Rerata \pm SD) & P value \\
\hline Gender & $\lesssim 33+18$ & $\delta 5 \% 6$ & 0.234 \\
\hline Age & $57.12 \pm 7.29$ & $56.09 \pm 7.89$ & 0.351 \\
\hline Hypertension period & $5.79 \pm 3.46$ & $5.46 \pm 2.91$ & 0.846 \\
\hline BMI & $24.28 \pm 3.52$ & $24.10 \pm 3.42$ & 0.818 \\
\hline
\end{tabular}


Table above shows that different test analysis was performed on the confounding factors, i.e. gender, age, hypertension period and obesity, in the respondents' characteristics based on left ventricular remodeling. Left ventricular remodeling occurred if the LVMI in female was $>97 \mathrm{~g} / \mathrm{m}^{2}$ and $110 \mathrm{~g} / \mathrm{m}^{2}>0.42$.

\section{Discussion}

Hypertension was still considered the primary health problem among the society. People with hypertension often developed abnormal heart structure and functions including left ventricular remodeling and hypertrophy. Left ventricular remodeling was the structural changes (dimension, mass and form) in the heart as a response towards hemodynamic loads related to neurohormonal activation $^{(10)}$.

Left ventricular hypertrophy occurred as a compensation to maintain to keep heart's pumping function adequate towards the chronic increase of preload and after-load. The chronology of ventricular load increase until cellular hypertrophy occurred was due to interactions among several systems ${ }^{(11)}$. Myocardial strain due to excessive volume loads or pressure loads stimulate cardiac fibroblast and myocytes expressed a number of fibrotic and growth factors including angiotensin II, insulin growth factor I (IGF I), IL-6, TGF- $\beta$, and endotelin-1 ${ }^{(12)}$.

All those humoral factors could trigger myocardial hypertrophy occurrence. Persistent hypertension stimulated RAAS (rennin, angiotensin II and aldosteron), endotelin- 1 and TGF- $\beta$ to trigger transition from fibroblast to myofibroblast. Myofibroblast then increase the production of extracellular protein matrix including fibronectin, laminin, collagen I and II which caused fibrosis progressivity ${ }^{(10)}$. The increase of cardiomyocyte size, extracellular matrix changes and fibrosis accumulation led to left ventricular remodeling. In echocardiography examination, left ventricular concentric remodeling occurred if the relative wall thickness (RWT) was $>0.42$ with left ventricular mass index was still within the normal range. The prevalence of left ventricular hypertrophy correlated with old age and the degree of hypertension severity, which ranged around $6 \%$ in young patients aged $<30$ years old, $43 \%$ in the age of $>69$ and $20-50 \%$ in mild to severe hypertension ${ }^{(13)}$.

From the respondents' data in this study, the author obtained 62 subjects ( 24 were male and 38 were female) aged 40-75 years old. Their hypertension history period ranged between $0,5-15$ years and they have undergone at least routine medication in polyclinic. Gender, age, hypertension history period and obesity affect the occurrence of left ventricular remodeling. Difference test analysis was performed on those four confounding factors using Chi-square and t-test statistical analysis and no significant result was obtained. In the respondents' data, those four factors did not give any significant difference.

No left ventricular hypertrophy was found in EKG examination as well (based on Romilt Estes criteria). The results of M-mode echocardiography showed that left ventricular mass index was within the normal range with the mean of $75.38 \pm 12.63 \mathrm{~g} / \mathrm{m}^{2}$ (the lowest was 49.44 and the highest was $97.92 \mathrm{~g} / \mathrm{m}^{2}$ ) while the mean of RWT was $0.36 \pm 0.06$ (the lowest was 0.28 and the highest was 0.48 ). No left ventricular hypertrophy was found in the data. Left ventricular geometric changes in hypertension patients were still within normal size or left ventricular remodeling. All respondents showed normal left ventricular systolic functions with the mean of EF by Teich amounted of $68.59 \pm 5.04$ (\%). Normokinetic was also found in regional wall motion based analysis based on echocardiography ${ }^{(14)}$.

In this study on tested rats, there was QT elongation related to the rats' blood pressure compared to the rats' left ventricular mass index. Another studies also showed the correlation between the value of arterial blood pressure and the average blood pressure with QT interval elongation in patients with hypertension. A study conducted by Latea et al. (2010) confirmed that anti-hypertension therapy could decrease QT interval related to decreased blood pressure and left ventricular mass index ${ }^{(15)}$. The result of this study also supported that of the previous ones where there was a significant correlation between QT interval and left ventricular mass index in respondents with hypertension. The data above show elongated QTc interval that correlated with the increase of left ventricular mass index with weak correlation $(\mathrm{r}=0.27, \mathrm{p}$ value $=0.030)$. The possible explanation on the weak correlation was because it was related to the hypertension period and the degree of hypertension severity. The respondents in this study had the hypertension period of 3-8 years and not very high blood pressure.

QT interval positively correlated with left ventricular mass index in hypertension patients who have not yet 
developed left ventricular hypertrophy. Repolarization impairment in this study might be due to left ventricular remodeling, i.e. fibrosis, extracellular matrix increase and perivascular fibrosis that caused conduction impairment. In this study, the QTc was longer in hypertension patients with left ventricular remodeling. In microscopic level, left ventricular hypertrophy including myocyte hypertrophy, fibrosis and increased interstitial collagen tissue would lead to action potential time elongation ${ }^{(16)}$. The heart of rats with hypertrophy would experience action potential elongation and specific impairment in potassium repolarization $\left(\mathrm{I}_{\mathrm{to}}\right)^{(17)}$.

Several studies showed data in which a correlation between QT interval and blood pressure in hypertension patients was found. This study showed a positive correlation between QT interval and systolic blood pressure $(\mathrm{r}=0.312, \mathrm{p}$ value $=0.014)$. Systolic blood pressure affect QT interval more significantly that it did diastolic blood pressure. The primary factor that was responsible for left ventricular hypertrophy was excessive pressure loads. It would lead to myocardial changes, i.e. increased left ventricular mass index due to remodeling or left ventricular hypertrophy ${ }^{(18)}$. Increased left ventricular mass index caused QT interval elongation. The previous studies showed a correlation between QT interval correlation and excessive sympathetic activities in essential hypertension patients ${ }^{(6)}$. In this study, hypertension patients' blood pressure evaluation results was still in control or increased up to level I (according to JNC VII), but the higher blood pressure correlated with QT interval elongation in respondents' data.

Left ventricular mass index was examined using echocardiography in which there was a limitation compared to other examinations such as magnetic resonance image. LVMI examination using M-mode echocardiography resulted in variabilities with the difference of nearly $5 \%$ which might contribute to the difference of 50 gram. The variabilities particularly occurred in measuring of wall thickness and determining the myocardial lining limit. For reproducibility, it was a bit better to use ASE measurement method compared to Penn ${ }^{(19)}$.

Based on Framingham data, RWT gave left underestimated ventricular hypertrophy measurement, which was $5 \%$, since it only used posterior wall thickness. Systolic blood pressure affected ventricular repolarization $^{(20)}$. Blood pressure kept changing from time to time and therefore, a measurement in one time could not represent a patient's blood pressure for 24 hours.

\section{Conclusion}

Left ventricular hypertrophy was rarely found in EKG examination of hypertension patients since this examination was highly specified but less sensitive. Another EKG impairment that often occurred in hypertension patients was QT interval elongation. The respondents' mean of QT interval was $390.40 \pm 30.73$ millisecond.

Echocardiography examination in hypertension patients showed normal left ventricular mass index (based on ASE recommendation, in female was $<95 \mathrm{~g} /$ $\mathrm{m}^{2}$ and in male was $<115 \mathrm{~g} / \mathrm{m}^{2}$ ) and RWT of above 0.42 which indicated left ventricular concentric remodeling. A weak correlation was found between QT interval with left ventricular mass index and systolic blood pressure. QT interval elongation was proportional to the increase of LVMI and high systolic blood pressure in the respondents.

Ethical Clearance: The research process involves participants in the survey using a questionnaire that was accordant with the ethical research principle based on the regulation of research ethic committee. The present study was carried out in accordance with the research principles and was approved by the Ethics Committee of Faculty of Medicine Universitas Airlangga, Indonesia. This study implemented the basic principle ethics of respect, beneficence, nonmaleficence, and justice.

Conflict of Interest: The researchers reports no conflict of interest of this work.

Source of Funding: This research is done with individual money.

\section{References}

1. Madden JM, O'flynn AM, Fitzgerald AP, Kearney PM. Correlation between short-term blood pressure variability and left-ventricular mass index: a metaanalysis. Hypertens Res. 2016;39(3):171.

2. ATHIYAH UMI, SUBARNIATI R, YUDA ANA. Medication Adherence in Elderly Patients with Hypertension. Asian J Pharm Clin Res. 10(8):16570.

3. Modesti PA, Ferrari A, Bazzini C, Costanzo G, Simonetti I, Taddei S, et al. Psychological predictors 
of the antihypertensive effects of music-guided slow breathing. J Hypertens. 2010;28(5):1097-103.

4. Garfinkel MS, Singhal A, Katz WA, Allan DA, Reshetar R, Schumacher Jr HR. Yoga-based intervention for carpal tunnel syndrome: a randomized trial. Jama. 1998;280(18):1601-3.

5. Schirmer SH, Sayed MMYA, Reil J-C, Ukena C, Linz D, Kindermann $M$, et al. Improvements in left ventricular hypertrophy and diastolic function following renal denervation: effects beyond blood pressure and heart rate reduction. J Am Coll Cardiol. 2014;63(18):1916-23.

6. Soliman EZ, Byington RP, Bigger JT, Evans G, Okin PM, Goff Jr DC, et al. Effect of intensive blood pressure lowering on left ventricular hypertrophy in patients with diabetes mellitus: Action to Control Cardiovascular Risk in Diabetes Blood Pressure Trial. Hypertension. 2015;66(6):1123-9.

7. Chundusu CM, Danbauchi SS, Okeahialam BN. Corrected QT Interval in Hypertension Seen in a Tertiary Health Institution in North Central Nigeria. 2018;

8. Sayogo S, Siregar P. Plasma Potassium Levels in Healthy Prehypertension Subjects and the Role of A High Potassium Drink. Curr Hypertens Rev. 2017;13(1):65-70.

9. Yhuwana YGY, Apsari R, Yasin M. Fiber optic sensor for heart rate detection. Optik (Stuttg). 2017;134:28-32.

10. Yamashina A, Tomiyama H, Arai T, Hirose K, Koji Y, Hirayama Y, et al. Brachial-ankle pulse wave velocity as a marker of atherosclerotic vascular damage and cardiovascular risk. Hypertens Res. 2003;26(8):615-22.

11. Shamir AR, Karembelkar A, Yabes J, Yao Y, Miskulin D, Gassman J, et al. Association of intradialytic hypertension with left ventricular mass in hypertensive hemodialysis patients enrolled in the blood pressure in dialysis (BID) study. Kidney Blood Press Res. 2018;43(3):882-92.

12. Weber $\mathrm{T}$, Protogerou A. Left ventricular hypertrophy, arterial stiffness and blood pressure: exploring the Bermuda Triangle. J Hypertens. 2019;37(2):280-1.
13. Milan A, Zocaro G, Leone D, Tosello F, Buraioli I, Schiavone D, et al. Current assessment of pulse wave velocity: comprehensive review of validation studies. J Hypertens. 2019;

14. Tokitsu T, Yamamoto E, Oike F, Hirata Y, Tsujita $\mathrm{K}$, Yamamuro $\mathrm{M}$, et al. Clinical significance of brachial-ankle pulse-wave velocity in patients with heart failure with preserved left ventricular ejection fraction. J Hypertens. 2018;36(3):560-8.

15. Latea L, Negrea SL, Bolboaca SD. Effects of valsartan and nebivolol on blood pressure, QT dispersion and left ventricular hypertrophy in hypertensive patients/Hipertansif hastalarda valsartan ve nebivololun, kan basinci, QT dagilimi ve sol ventrikül hipertrofisi üzerine etkileri. Dicle Tip Derg. 2010;37(2):81.

16. Julian RJ, Mirsalimi SM. Blood oxygen concentration of fast-growing and slow-growing broiler chickens, and chickens with ascites from right ventricular failure. Avian Dis. 1992;730-2.

17. Yamashina A, Tomiyama H, Takeda K, Tsuda H, Arai T, Hirose K, et al. Validity, reproducibility, and clinical significance of noninvasive brachialankle pulse wave velocity measurement. Hypertens Res. 2002;25(3):359-64.

18. Pusuroglu H, Cakmak HA, Erturk M, Akgul O, Akkaya E, Tosu AR, et al. Assessment of the relation between mean platelet volume, non-dipping blood pressure pattern, and left ventricular mass index in sustained hypertension. Med Sci Monit Int Med J Exp Clin Res. 2014;20:2020.

19. Cuspidi C, Facchetti R, Bombelli M, Tadic M, Sala C, Grassi G, et al. High Normal Blood Pressure and Left Ventricular Hypertrophy Echocardiographic Findings From the PAMELA Population. Hypertension. 2019;73(3):612-9.

20. Pieruzzi F, Antolini L, Salerno FR, Giussani M, Brambilla P, Galbiati S, et al. The role of blood pressure, body weight and fat distribution on left ventricular mass, diastolic function and cardiac geometry in children. J Hypertens. 2015;33(6):1182-92. 